\title{
Persepsi dan Preferensi Petani terhadap Karakteristik Varietas Unggul Padi Gogo di Kabupaten Boyolali, Jawa Tengah
}

\section{Farmer's Perceptions and Preferences on The Characteristics of Upland Rice Superior Varieties in Boyolali District, Central Java}

\author{
Dewi Sahara, Chanifah, Elly Kurniyati, dan Budi Hartoyo \\ Balai Pengkajian Teknologi Pertanian (BPTP) Jawa Tengah \\ Jalan Soekarno-Hatta Km. 26 No. 10 Bergas, Kab. Semarang Jawa Tengah \\ Email: dewisahara.ds@gmail.com
}

Diterima: 18 Februari 2021

Revisi: 31 Agustus 2021

Disetujui: 22 November 2021

\begin{abstract}
ABSTRAK
Perluasan tanam padi saat ini di lahan sawah non irigasi dengan varietas unggul baru (VUB) padi gogo. Penelitian bertujuan untuk mengetahui persepsi petani terhadap karakter tanaman, karakter beras dan karakter nasi, serta mengetahui preferensi petani terhadap karakter nasi VUB padi gogo. Penelitian dilaksanakan di Desa Tegalgiri, Kecamatan Nogosari, Kabupaten Boyolali pada bulan April-Juli 2020 dengan metode survei kepada petani yang menanam padi gogo varietas Rindang 1, Rindang 2, Inpago 10, Inpago 12 dan Ciherang. Data dianalisis secara deskriptif dengan nilai rata-rata, teknik skoring dengan Perceptual Mapping dan nilai persentase. Hasil penelitian menunjukkan petani memiliki persepsi yang baik terhadap karakter tanaman pada varietas Inpago 12 karena mempunyai produktivitas tertinggi $(5,81$ ton/ha GKG), terhadap karakter beras pada varietas Rindang 1 dan Inpago 12, terhadap karakter nasi pada varietas Rindang 2, Inpago 10 dan Ciherang. Preferensi petani terhadap karakter nasi VUB padi gogo tertinggi diperoleh pada varietas Rindang 2 ( 96,7 persen) karena memiliki rasa nasi yang lebih manis dan tekstur nasi pulen. Oleh karena itu untuk mengembangkan varietas padi gogo perlu memerhatikan produktivitas tanaman, warna dan ukuran beras serta rasa dan tekstur nasi.

kata kunci: produktivitas tanaman, warna beras, ukuran beras, rasa nasi, tekstur nasi
\end{abstract}

\section{ABSTRACT}

The current expansion of rice planting in non irrigated rice fields is using the new superior varieties (NSV) of upland rice. This study aimed to determine farmers' perceptions of plant, grain, and rice characters and to determine farmers' preferences for the grain characters of NSV upland rice. The research was conducted in Tegalgiri Village, Nogosari Subdistrict, Boyolali District from April to July 2020 with a survey method to farmers who planted rice varieties Rindang 1, Rindang 2, Inpago 10, Inpago 12, and Ciherang. Data were analyzed descriptively with average values, scoring techniques with Perceptual Mapping, and percentage values. The results showed that farmers had a good perception of the plant characters of the Inpago 12 because it had the highest productivity (5.81 tons/ha GKG), the grain characters of the Rindang 1 and Inpago 12, the rice characters of the Rindang 2, Inpago 10 and Ciherang. The highest preference of farmers for NSV rice character was obtained in the Rindang 2 (96.7 percent) because it had a sweeter taste and fluffier rice texture. Therefore, to develop upland rice varieties, it is necessary to pay attention to plant productivity, the color and size of the grain, and the taste and texture of the rice.

keywords: plant productivity, grain color, grain size, rice taste, rice texture

\section{PENDAHULUAN}

$\mathrm{D}$ Indonesia beras merupakan salah satu komoditas pangan pokok dengan tingkat konsumsi dan status sosial tinggi dibandingkan bahan pangan lainnya. Total konsumsi beras makin tinggi sejalan dengan pertambahan jumlah penduduk. Konsumsi beras pada tahun 2017 sebesar 89,05 kg/kapita/tahun meningkat menjadi $94,9 \mathrm{~kg} / \mathrm{kapita} / \mathrm{tahun}$ atau terjadi kenaikan 6,36 persen (Wardani, 2019). Selama beras masih menjadi pangan pokok bagi masyarakat, maka perlu ada upaya untuk meningkatkan produksi padi.

Peningkatan produksi padi saat ini sulit dilakukan dengan memperluas areal tanam di lahan sawah karena berkurangnya lahan sawah 
setiap tahunnya, sehingga perluasan tanam padi diarahkan ke lahan kering atau lahan sawah tadah hujan menggunakan varietas padi gogo (Hasrawati, dkk., 2017; Sunanto dan Rauf, 2018). Pengembangan padi gogo merupakan salah satu program pemerintah untuk meningkatkan produksi dan mendukung kecukupan pangan masyarakat (Saleh, dkk., 2020).

Jawa Tengah merupakan salah satu daerah penyangga pangan nasional yang memiliki potensi lahan sawah non irigasi/lahan sawah tadah hujan seluas 77.532 ha. Sebanyak 13,56 persen dari luas lahan tersebut terletak di Kabupaten Boyolali. Lahan sawah non irigasi/ tadah hujan pada umumnya ditanami dengan padi gogo. Peningkatan produktivitas padi gogo lebih lambat dibandingkan produktivitas padi sawah. Rata-rata produktivitas padi gogo lima tahun terakhir (2014-2018) adalah 4,20 \pm 1,05 ton/ha dibandingkan produktivitas padi sawah 5,76 $\pm 2,61$ ton/ha (BPS Provinsi Jawa Tengah, 2019) sehingga kontribusi padi gogo terhadap produksi padi nasional 90 persen lebih rendah dibandingkan kontribusi produksi padi sawah (Pasolon, dkk., 2017). Sadimantara, dkk. (2018) mengemukakan bahwa selain produktivitas yang rendah, produksi padi gogo memiliki kualitas yang rendah dan umur tanaman yang lebih lama (3-4 bulan). Oleh karena itu perlu adanya perbaikan sifat genetik tanaman melalui Varietas Unggul Baru (VUB).
VUB padi gogo merupakan komponen teknologi yang berhasil meningkatkan produksi tanaman (Husnain, dkk., 2016) karena memiliki karakteristik berdaya hasil tinggi, tahan terhadap penyakit utama, dan berumur genjah sehingga dapat dikembangkan dengan pola tanam tertentu, serta memiliki rasa nasi enak dengan kadar protein yang relatif tinggi (Nazirah, dkk., 2015). Pengembangan VUB padi gogo akan berhasil jika petani mengadopsi varietas tersebut. Proses adopsi VUB padi gogo dipengaruhi oleh persepsi dan preferensi petani terhadap karakter tanaman dan karakter hasil yang diperoleh. Persepsi dan preferensi petani menjadi sangat penting karena menjadi dasar pertimbangan untuk menerima atau menolak VUB tersebut.

Persepsi petani merupakan sebuah proses pemahaman dalam memperoleh pengetahuan atau inovasi teknologi VUB padi gogo yang akan diadopsi pada masa yang akan datang (Krisnawati, dkk., 2013; Widyastuti, 2016; Rahayu, dkk., 2019a), sedangkan preferensi petani merupakan tingkat kesukaan petani terhadap kombinasi berbagai atribut dari VUB padi gogo (Yusuf dan Fitria, 2017). Penelitian bertujuan untuk mengetahui persepsi petani terhadap karakter tanaman VUB padi gogo, karakter beras dan karakter nasi, serta mengetahui preferensi petani terhadap karakter nasi VUB padi gogo.

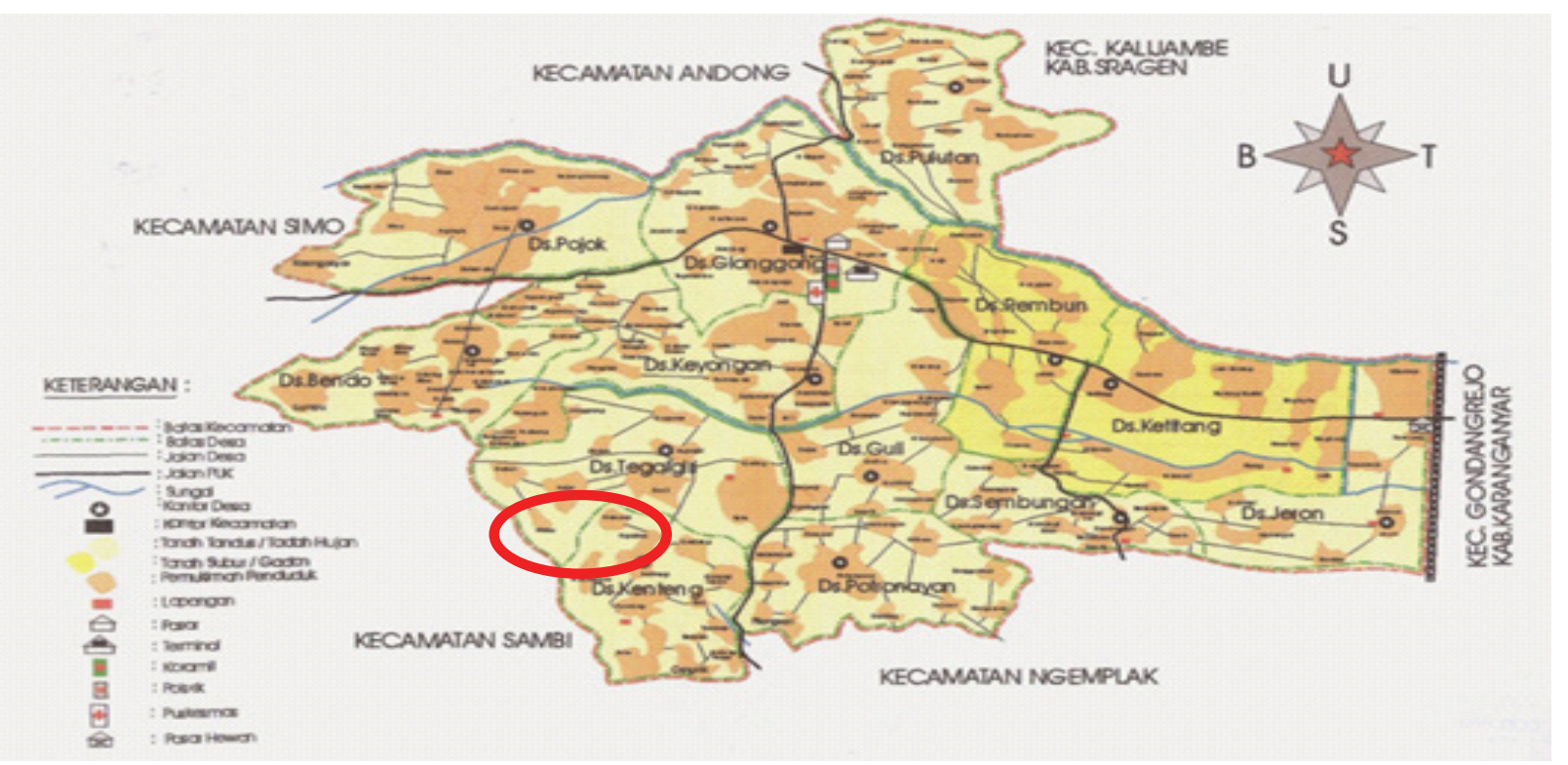

Gambar 1. Peta Desa Tegalgiri Kecamatan Nogosari Kabupaten Boyolali. 


\section{METODOLOGI}

\subsection{Lokasi dan Waktu Penelitian}

Penelitian dilaksanakan di Desa Tegalgiri, Kecamatan Nogosari, Kabupaten Boyolali pada April-Juli 2020 (Gambar 1). Pemilihan lokasi penelitian dilakukan dengan sengaja atas dasar pertimbangan Kabupaten Boyolali merupakan salah satu wilayah pengembangan padi gogo di Jawa Tengah dengan lokasi terluas dan berupa hamparan berada di Desa Tegalgiri.

\subsection{Metode Pengumpulan Data}

Data yang dikumpulkan adalah data primer dan data sekunder. Data primer dikumpulkan dengan metode survei kepada 30 petani yang tergabung ke dalam Kelompok Tani Subur yang menanam padi gogo varietas Inpago 10, Inpago 12, Rindang 1, Rindang 2 dan Ciherang. Jenis data primer yang dikumpulkan meliputi: (i) karakter tanaman, yaitu tinggi tanaman, umur tanaman, jumlah anakan produktif, ketahanan terhadap hama penyakit, dan hasil gabah; (ii) karakter beras, yaitu ukuran dan warna beras; dan (iii) karakter nasi, yaitu warna, rasa, aroma dan tingkat kepulenan nasi. Data sekunder diperoleh dari BPS Provinsi Jawa Tengah dan beberapa publikasi hasil penelitian lainnya untuk mendukung pembahasan.

\subsection{Metode Analisis Data}

Pertama, untuk mengetahui karakter tanaman data yang diperoleh dianalisis dengan nilai rata-rata dan simpangan baku. Kedua, data yang diperoleh untuk mengetahui persepsi petani terhadap karakter tanaman, beras dan nasi merupakan data ordinal yang dianalisis dengan teknik skoring. Teknik skoring juga digunakan oleh Darsani dan Koesrini (2018) untuk mengukur tingkat persepsi petani terhadap karakter varietas unggul padi di lahan rawa pasang surut, Rahayu, dkk., (2019b) untuk mengukur respons dan kepuasan petani terhadap diseminasi teknologi Pengelolaan Tanaman Terpadu (PTT) padi sawah di Kabupaten Sigi, Sulawesi Tengah. Persepsi petani dinilai menggunakan skala Likert dengan nilai 1-3 dengan kategori tidak setuju, raguragu dan setuju. Selanjutnya data persepsi dianalisis menggunakan skoring dengan formula (Theresia, dkk., 2016) :
Nilai skor $=\frac{n_{i} \cdot s_{i}}{N_{i}}$

Keterangan:

$\mathrm{ni}=$ jumlah responden pada kolom ke-i $(i=1,2,3)$

si $=$ skor pernyataan ke-i $(i=1,2,3)$

$\mathrm{Ni}=$ jumlah responden pada baris ke-1 $(i=1,2,3)$

Persepsi petani terhadap karakter tanaman VUB padi dinilai dengan 5 indikator, yaitu tinggi tanaman, umur tanaman, jumlah anakan produktif, ketahanan terhadap hama/penyakit dan produksi yang dihasilkan, persepsi terhadap karakter beras dinilai dengan 2 indikator, yaitu warna dan ukuran beras, sedangkan persepsi terhadap karakter nasi dinilai dengan 4 indikator, yaitu warna, rasa, aroma dan tekstur nasi.

Pengkategorian persepsi petani terhadap karakter tanaman, beras dan nasi VUB padi gogo menggunakan skala interval 3 kelas, yaitu tinggi, sedang dan rendah. Berdasarkan nilai tersebut maka kriteria tingkat persepsi adalah : (i) persepsi rendah (skala 1,00-1,66); (ii) persepsi sedang (skala 1,67-2,33); dan (iii) persepsi tinggi (skala 2,34-3,00) dengan rumus sebagai berikut (Theresia, dkk., 2016) :

skala interval $=\frac{\text { nilai tertinggi }- \text { nilai terendah }}{\text { jumlah skala interval }}$

Keragaan persepsi petani terhadap karakter tanaman, beras dan nasi digambarkan dengan teknik perceptual mapping, yaitu dengan membuat grafik sarang laba-laba yang merupakan nilai jumlah dalam bentuk grafik dua dimensi (Theresia, dkk., 2016).

Ketiga, untuk mengevaluasi preferensi petaniterhadapkarakternasi, datayang diperoleh dianalisis secara deskriptif menggunakan nilai persentase yang digambarkan dengan diagram batang.

\section{HASIL DAN PEMBAHASAN}

\subsection{Karakter Tanaman VUB Padi Gogo}

Empat varietas unggul padi gogo yang baru dikembangkan petani di lokasi kegiatan adalah Rindang 1, Rindang 2, Inpago 10, dan Inpago 12 , sedangkan varietas Ciherang merupakan varietas yang sudah lama. Berdasarkan hasil pengamatan terhadap tinggi tanaman, umur 
tanaman, jumlah anakan produktif dan hasil tanaman menunjukkan terdapat keragaman antar varietas (Tabel 1). mencukupi kebutuhan tanaman maka pengisian malai menjadi tidak sempurna/tidak bernas. Ritonga, dkk. (2020) bahwa jumlah anakan

Tabel 1. Karakter Tanaman VUB Padi Gogo pada Saat Panen

\begin{tabular}{|c|c|c|c|c|c|c|}
\hline \multirow{2}{*}{ No } & \multirow{2}{*}{$\begin{array}{c}\text { Karakter } \\
\text { Tanaman } \\
\end{array}$} & \multicolumn{5}{|c|}{ Varietas } \\
\hline & & Rindang 1 & Rindang 2 & Inpago 10 & Inpago 12 & Ciherang \\
\hline 1. & $\begin{array}{l}\text { Tinggi } \\
\text { tanaman }(\mathrm{cm})\end{array}$ & $124,07 \pm 13,09$ & $129,07 \pm 11,01$ & $113,77 \pm 11,18$ & $110,95 \pm 15,69$ & $91,85+8,27$ \\
\hline 2. & $\begin{array}{l}\text { Jumlah } \\
\text { anakan } \\
\text { produktif } \\
\text { (buah) }\end{array}$ & $10,55 \pm 1,42$ & $10,22 \pm 1,84$ & $10,75 \pm 2,86$ & $11,07 \pm 2,27$ & $12,27 \pm 3,21$ \\
\hline 3. & $\begin{array}{l}\text { Umur tanaman } \\
\text { (HST) }\end{array}$ & 98 & 96 & 85 & 87 & 95 \\
\hline 4. & $\begin{array}{l}\text { Produktivitas } \\
\text { (kg/ha GKG) }\end{array}$ & $5,05 \pm 1,54$ & $3,99 \pm 1,37$ & $4,65 \pm 1,37$ & $5,81 \pm 2,32$ & $4,28 \pm 1,64$ \\
\hline
\end{tabular}

Tanaman tertinggi pada saat panen adalah tanaman padivarietas Rindang 2, yaitu $129,07 \mathrm{~cm}$, diikuti Rindang 1 (124,07 cm), Inpago $10(113,77$ $\mathrm{cm})$, Inpago $12(110,95 \mathrm{~cm})$, dan yang terendah adalah varietas Ciherang 91,85 cm. Perbedaan tinggi tanaman tersebut lebih disebabkan oleh perbedaan genetik varietas dibandingkan faktor lingkungan. Secara genetik sesuai dengan deskripsinya, varietas Rindang 1 dan Rindang 2 memiliki postur tinggi tanaman yang cukup tinggi masing-masing dapat mencapai $130 \mathrm{~cm}$ dan $138 \mathrm{~cm}$, dibandingkan dengan varietas Inpago 10 dan Inpago 12 yang hanya dapat mencapai tinggi $104 \mathrm{~cm}$ dan Ciherang setinggi 107-115 $\mathrm{cm}$ (Badan Penelitian dan Pengembangan Pertanian, 2019). Nazirah dan Damanik (2015) menyatakan bahwa keragaman pertumbuhan tanaman antar varietas dapat disebabkan oleh perbedaan susunan genetik tanaman.

Jumlah anakan produktif tertinggi diperoleh pada varietas Ciherang dengan rata-rata 12,27 anakan dibandingkan varietas lainnya. Varietas Ciherang merupakan varietas padi sawah yang memiliki karakter genetik yang berpotensi menghasilkan jumlah anakan lebih banyak dibandingkan varietas padi gogo lainnya. Meskipun demikian, tidak semua anakan yang terbentuk dapat menghasilkan malai berisi gabah apabila faktor-faktor lain yang mendukung tidak memadai, seperti tidak cukupnya jumlah fotosintat (karbohidrat) pada tanaman. Translokasi dan akumulasi hasil fotosintat dalam batang dan daun sangat menentukan tingkat pengisian gabah (Hamdani dan Murtiani, 2017) sehingga apabila hasil fotosintat tidak produktif belum menunjukkan jumlah anakan yang dapat menghasilkan gabah, karena akan ada anakan yang mati dan gagal memproduksi gabah. Dengan demikian meskipun jumlah anakan varietas Ciherang tertinggi, namun tidak semuanya dapat menghasilkan gabah sehingga produktivitas yang diperoleh rendah.

Berbeda dengan varietas Ciherang, varietas Rindang 2 mempunyai jumlah anakan produktif terendah sehingga produktivitas yang diperoleh juga terendah, yaitu hanya 3,99 ton/ha GKG. Rendahnya jumlah anakan dan produktivitas varietas Rindang 2, didukung hasil penelitian Shoidah dan Adnan (2021) bahwa padi gogo varietas Rindang 2 rata-rata memiliki jumlah anakan terendah dibanding varietas lainnya, hanya 3,2 buah, sementara jumlah anakan varietas lainnya rata-rata lebih dari 3,2 buah. Demikian pula dengan produktivitas padi varietas Rindang 2 juga terendah, yaitu 2,3 ton/ ha. Berbeda dengan hasil penelitian Haryati, dkk. (2020) di Kabupaten Majalengka varietas Rindang 2 mempunyai produktivitas lebih tinggi, yaitu 6,15 ton/ha GKG. Perbedaan produktivitas ini diduga disebabkan oleh perbedaan lingkungan tumbuh dan sistem usahatani yang berbeda oleh petani. Kikuta, dkk. (2016) menyatakan bahwa perbedaan hasil padi gogo dapat disebabkan oleh kondisi topografi yang berbeda dan sikap petani dalam melakukan aktivitas usahatani.

Serangan hama penyakit pada tanaman di lokasi kegiatan yang ditemui adalah hama Wereng Batang Cokelat (WBC), hama penggerek batang dan penyakit blas. Meskipun 


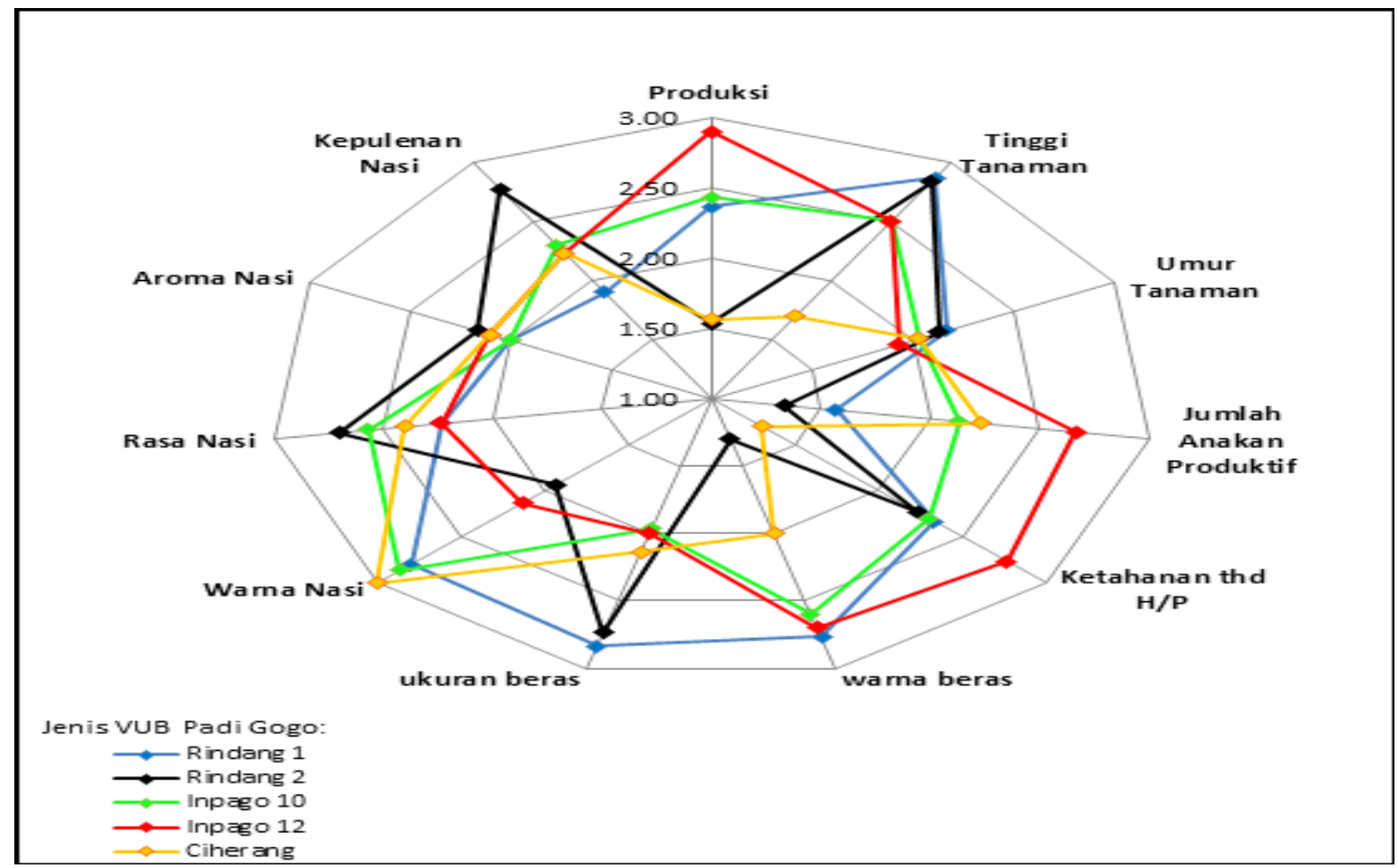

Gambar 2. Persepsi Petani terhadap Tanaman, Beras dan Nasi VUB Padi di Desa Tegalgiri, Kecamatan Nogosari, Kabupaten Boyolali, 2020

ditemui adanya serangan, namun tingkat serangan tersebut tergolong ke dalam serangan ringan, yaitu antara $1-5$ persen. Serangan hama penyakit tanaman yang lebih tinggi ditemui pada varietas Ciherang, sedangkan varietas lainnya lebih tahan terhadap serangan hama penyakit. Selain karena daya tahan tanaman, petani juga aktif mengendalikan serangan menggunakan pestisida nabati (Bioprotektor), selain pestisida kimia.

Umur panen tanaman padi gogo berkisar antara 85-98 hari setelah tanam (HST) atau 103-116 hari setelah semai (HSS). Tanaman padi gogo yang panen terlebih dahulu adalah Inpago 10, yaitu 85 HST, diikuti oleh Inpago 12 dengan umur 87 HST, Ciherang umur 95 HST, Rindang 2 umur 96 HST, dan Rindang 1 umur 96 HST. Umur panen padi gogo di lokasi kegiatan lebih cepat dibanding umur panen sesuai deskripsinya, yaitu berkisar antara 111-125 hari setelah tanam benih (Badan Penelitian dan Pengembangan Pertanian, 2019). Penelitian Hermanasari, dkk. (2017) mendapatkan umur panen varietas Inpago 10 dan Inpago 12 di Kabupaten Kebumen adalah 115 dan 116 hari, sedangkan umur panen padi gogo varietas Inpago 10 di Yogyakarta adalah 112 hari (Sutaryo dan Widodo, 2018). Perbedaan umur panen dapat dipengaruhi oleh lingkungan tempat tumbuh tanaman.

\subsection{Persepsi Petani terhadap Karakter Tanaman, Beras dan Nasi VUB Padi Gogo}

Keragaan persepsi petani terhadap karakter tanaman, beras dan nasi varietas unggul padi gogo ditampilkan pada Gambar 2. Persepsi tinggi mengindikasikan petani mempunyai persepsi yang baik, persepsi sedang mengindikasikan petani mempunyai persepsi yang biasa sedangkan persepsi rendah mengindikasikan petani mempunyai persepsi yang kurang baik terhadap indikator tertentu.

\subsubsection{Persepsi Petani terhadap Karakter Tanaman}

Petani mempunyai persepsi baik (persepsi tinggi) terhadap varietas Inpago 12 terutama terhadap semua indikator dengan rata-rata skor 2.55 , kecuali terhadap umur tanaman petani mempunyai persepsi sedang dengan rata-rata skor 1,93. Hal ini dikarenakan umur tanaman padi gogo antar varietas relatif sama, yaitu di kisaran 85-96 HST, sehingga petani mempunyai persepsi yang biasa (persepsi sedang) terhadap umur tanaman. Berbeda dengan penelitian Yusuf 
dan Fitria (2017) bahwa petani di Provinsi Aceh menyukai tanaman padi yang berumur sedang, yaitu 110-120 hari setelah semai dibandingkan tanaman padi yang berumur genjah, namun petani di Cilacap lebih menyukai tanaman padi yang berumur genjah agar petani dapat memanfaatkan dan memaksimalkan lahan yang dikelola (Prayoga, dkk., 2018).

Persepsi petani tertinggi terhadap karakter tanaman padi varietas Inpago 12 diperoleh pada indikator hasil gabah dengan rata-rata skor 2,90. Produktivitas Inpago 12 tertinggi dibandingkan varietas lainnya sehingga hampir semua petani (93,33 persen petani) mempunyai persepsi yang tinggi terhadap produktivitas padi Inpago 12. Produktivitas yang diperoleh lebih tinggi 35,75 persen dari varietas Ciherang yang biasa ditanam petani. Persepsi tinggi terhadap produktivitas padi juga diperoleh pada penelitian Indratanaya, dkk. (2019) pada petani padi di Denpasar. Persepsi tersebut menggambarkan petani mempunyai respons yang tinggi terhadap indikator produktivitas tanaman dibandingkan indikator lainnya.

Petani mempersepsikan biasa terhadap karakter tanaman padi varietas lainnya (persepsi sedang), diindikasikan dengan ratarata skor 1,77-2,28. Rata-rata skor terendah $(1,77)$ yaitu padi varietas Ciherang pada semua indikator. Hal ini dikarenakan varietas Ciherang merupakan varietas yang biasa ditanam oleh petani dan secara morfologis tanaman varietas Ciherang mempunyai rata-rata yang lebih rendah dibanding varietas lainnya kecuali jumlah anakan produktif.

Persepsi sedang dengan nilai terendah kedua (rata-rata skor 2,01) diperoleh pada varietas Rindang 2 , terutama terhadap indikator jumlah anakan produktif (rata-rata skor 1,33) dan produksi gabah yang dihasilkan (ratarata skor 1,53). Rendahnya anakan produktif pada varietas Rindang 2 diduga karena faktor genetik. Hasil penelitian Haryati, dkk. (2020), dari empat varietas yang dicoba, yaitu Rindang 2, Pajajaran, Cakrabuana dan Munawacita, Rindang 2 memiliki jumlah anakan terendah rata-rata 12,27 buah yang berbeda nyata dengan varietas lainnya. Dengan jumlah anakan produktif yang rendah maka hasil yang diperoleh juga rendah, bahkan produksi Rindang 2 yang diperoleh terendah, yaitu 3,99 ton/ha GKG.
Persepsi sedang pada varietas Rindang 1 mempunyai nilai rata-rata skor 2,26. Persepsi sedang pada varietas Rindang 1 terutama pada indikator jumlah anakan produktif mempunyai nilai skor terendah, yaitu 1,57. Rendahnya persepsi petani terhadap jumlah anakan produktif dikarenakan jumlah anakan yang terbentuk pada Rindang 1 rata-rata 10,5 buah lebih rendah dibanding anakan produktif pada varietas Inpago 10, Inpago 12 dan Ciherang. Sejalan dengan hasil penelitian Ritonga dkk. (2020) mendapatkan anakan produktif varietas Rindang 1 rata-rata 8,96 buah lebih sedikit dari varietas Inpago 8, 9, 11 dan 12. Sedikit banyaknya jumlah anakan produktif ditentukan oleh sifat genetik tanaman (Nurhasanah, dkk. 2017).

Rata-rata nilai skor persepsi pada varietas Inpago 10 adalah 2,28 berada pada kategori persepsi sedang. Nilai semua indikator karakter tanaman Inpago 10 berada di kisaran 2,03-2,50, nilai terendah pada indikator umur tanaman dan tertinggi pada indikator tinggi tanaman. Hasil ini mengindikasikan karakter tanaman Inpago 10 berada pada kondisi biasa dan tidak ada indikator yang lebih dominan dari varietas lainnya.

Indikator ketahanan terhadap hama penyakit tanaman dikategorikan petani ke dalam persepsi sedang pada varietas Rindang 1, Rindang 2, Inpago 10 dan Inpago 12, dan persepsi rendah pada varietas Ciherang. Hal ini dikarenakan varietas Ciherang lebih rentan terhadap serangan hama dan penyakit tanaman di lokasi kegiatan dibanding varietas lainnya yang lebih tahan.

\subsubsection{Persepsi Petani terhadap Karakter Beras}

Beras merupakan bahan pangan karbohidrat yang dikonsumsi dalam bentuk utuh, oleh karena itu mutu butir beras akan memengaruhi persepsi konsumen. Mutu beras ditentukan oleh gabungan karakter fisik, kimia, dan nutrisi (Mardiah, dkk., 2016). Namun, faktor yang dapat dinilai oleh konsumen secara langsung dan dijadikan sebagai penentu dalam pemilihan beras adalah karakter fisik seperti warna, bentuk, aroma, ukuran, persentase beras kepala, dan material pengotor. Karakter morfologi beras (bentuk, panjang, lebar dan 
tebal) merupakan karakter yang sangat mudah diamati dalam menentukan perbedaan varietas beras (Hanas, dkk., 2017).

Dalam kegiatan ini persepsi petani terhadap karakter beras hanya dilihat dari dua indikator, yaitu warna dan ukuran beras karena dua indikator tersebut yang menjadi pertimbangan konsumen dalam memilih dan mengonsumsi beras. Berdasarkan indikator tersebut maka persepsi tinggi diperoleh pada beras varietas Rindang 1 (rata-rata skor 2,80) dan Inpago 12 (rata-rata skor 2,35), sedangkan persepsi sedang terhadap karakter beras diperoleh pada varietas Rindang 2 (rata-rata skor 2,01), Inpago 10 (rata-rata skor 2,28) dan Ciherang (ratarata skor 2,07). Darsani dan Koesrini (2018) mengungkapkan bahwa petani mempunyai persepsi yang tinggi terhadap mutu beras, dilihat dari warna beras yang putih, bersih dan ukuran beras yang utuh/tidak pecah. Yusuf dan Fitria (2018) mengemukakan bahwa petani mempunyai persepsi yang tinggi terhadap bentuk, ukuran dan warna gabah karena akan memengaruhi bentuk dan ukuran beras yang diinginkan konsumen.

Indikator warna beras dipersepsikan biasa/ sedang pada varietas Rindang 2 dan Ciherang karena warna beras pada varietas tersebut agak buram dibandingkan varietas Rindang 1, Inpago 10 dan Inpago 12 yang memiliki warna putih/cerah sehingga dipersepsikan tinggi oleh petani. Sebagaimana penelitian Hermanasari, dkk. (2017) bahwa warna beras padi rata-rata putih kecuali varietas tertentu memiliki warna merah. Ukuran beras dipersepsikan biasa pada varietas Inpago 10, Inpago 12 dan Ciherang karena ukuran beras ketiga varietas tersebut relatif sama, sedangkan ukuran beras varietas Rindang 1 dan Rindang 2 dipersepsikan tinggi karena mempunyai ukuran yang ideal, yaitu tidak terlalu gemuk dan tidak terlalu ramping sehingga beras tidak mudah patah (Rohaeni, dkk., 2012).

\subsubsection{Persepsi Petani terhadap Karakter Nasi}

Persepsi petani terhadap keragaan nasi VUB padi dilihat dari empat indikator, yaitu warna, rasa, aroma dan tekstur/kepulenan nasi. Petani mempunyai persepsi sedang pada varietas Rindang 1 dengan rata-rata skor 2,23 dan Inpago 12 dengan skor rata-rata 2,18, sedangkan persepsi tinggi diperoleh pada varietas Rindang 2 dengan rata-rata skor 2,39, Inpago 10 dan Ciherang dengan rata-rata skor 2,43 .

Petani mempunyai persepsi tinggi terhadap indikator warna nasi varietas Rindang 1 , Inpago 10 dan Ciherang, sedangkan warna nasi varietas Rindang 2 dan Inpago 12 dipersepsikan sedang. Persepsi tinggi pada indikator warna nasi menunjukkan warna nasi dari ketiga varietas tersebut lebih putih dibandingkan warna nasi dua varietas yang dipersepsikan sedang. Perbedaan warna nasi pada kelima varietas selain disebabkan oleh sifat genetik tanaman juga dapat disebabkan oleh derajat sosoh, kandungan amilosa, dan perubahan selama penyimpanan beras. Derajat sosoh yang tinggi mengakibatkan banyak kulit ari terlepas sehingga beras lebih putih (Setyowati dan Kurniawati, 2015; Darsani dan Koesrini, 2018).

Indikator rasa nasi dipersepsikan tinggi oleh petani pada varietas Rindang 2, Inpago 10, dan Ciherang, persepsi sedang pada rasa nasi varietas Rindang 1 dan Inpago 12. Rasa nasi yang dipersepsikan tinggi oleh responden mempunyai rasa sedikit lebih manis, dibandingkan rasa nasi varietas yang dipersepsikan sedang dengan rasa biasa.

Petani mempersepsikan aroma nasi semua varietas ke dalam kategori persepsi sedang (biasa) karena tidak ada aroma harum sebagaimana beras aromatik. Sebagaimana penelitian Ar-Rozi (2020) mendapatkan hasil yang sama terhadap persepsi responden terhadap aroma beras organik dan anorganik yang mempunyai persepsi cukup (sedang) karena responden mengidentifikasi tidak adanya aroma wangi pada beras.

Petani mempersepsikan tekstur nasi varietas Rindang 2 ke dalam kategori persepsi tinggi, sedangkan tekstur nasi empat varietas lainnya dipersepsikan biasa. Persepsi tinggi tekstur nasi pada varietas Rindang 2 disebabkan tekstur nasi yang lebih pulen dibandingkan varietas Ciherang, sedangkan varietas Rindang 1, Inpago 10 dan Inpago 12 memiliki tekstur nasi agak pera. Darsani dan Koesrini (2018) mengemukakan bahwa tingkat kepulenan nasi 


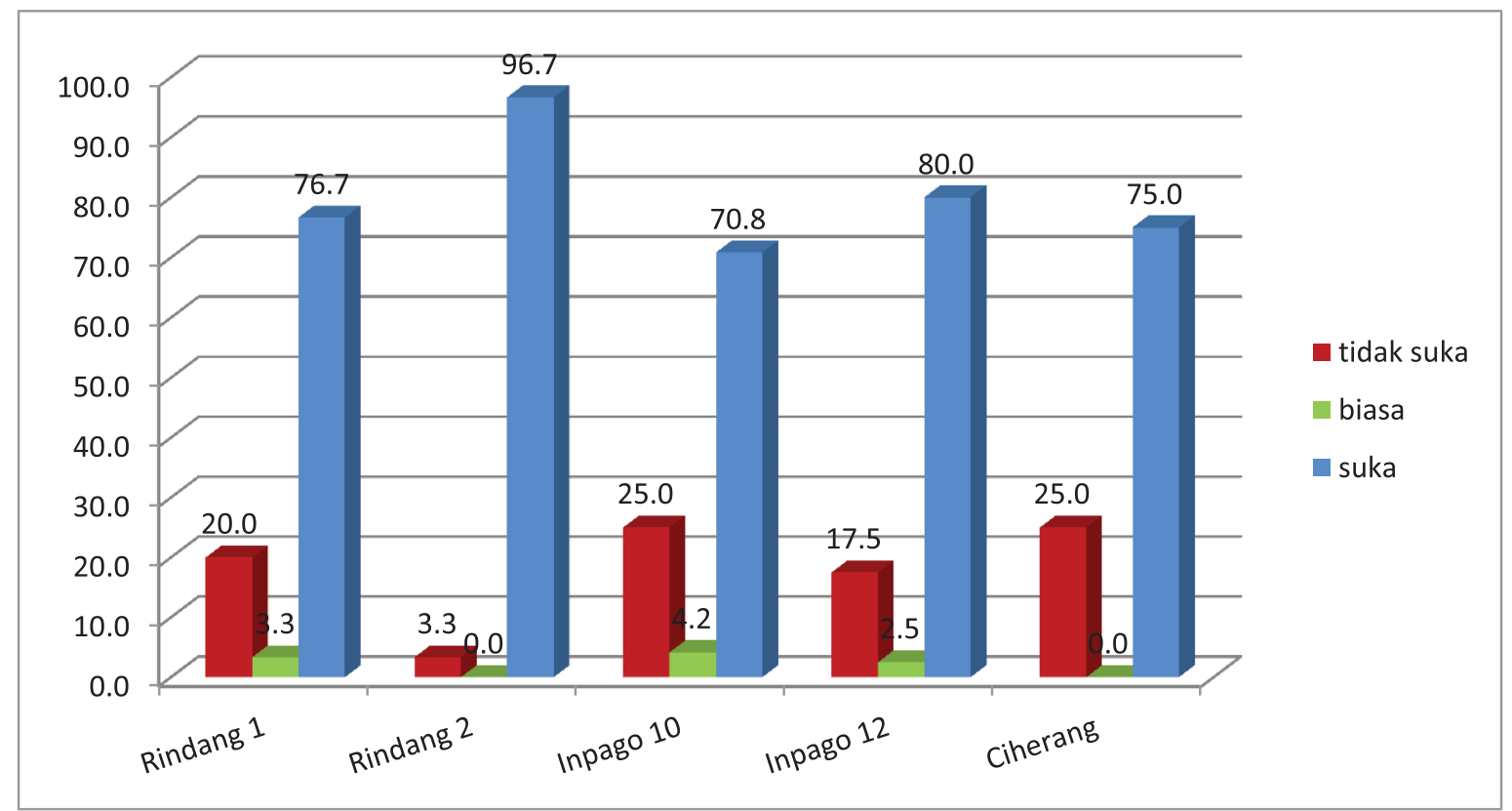

Gambar 3. Preferensi Petani terhadap Nasi Varietas Unggul Padi Gogo di Desa Tegalgiri, Kecamatan Nogosari, Kabupaten Boyolali, 2020

dipengaruhi oleh kadar amilosa pada beras. Kadar amilosa beras Rindang 2 terkecil dibandingkan kadar amilosa varietas lain, yaitu 16,4 persen dibandingkan Rindang 1 (26,5 persen), Inpago 10 (25,0 persen), Inpago 12 (22,8 persen) dan Ciherang (23 persen) (Badan Penelitian dan Pengembangan Pertanian, 2019). Makin tinggi kadar amilosa suatu beras, maka tekstur nasi makin pera, sebaliknya makin rendah kadar amilosa beras maka tekstur nasi makin pulen.

\subsection{Preferensi Petani terhadap Nasi VUB Padi}

Preferensi petani terhadap nasi VUB padi dipengaruhi oleh beberapa indikator, yaitu warna, aroma, tekstur dan rasa nasi. Yusuf dan Fitria (2017) menyatakan bahwa tekstur nasi pulen lebih disukai oleh masyarakat. Selain itu, warna nasi yang putih bersih dan aroma nasi yang harum juga menjadi pilihan masyarakat untuk mengonsumsinya.

Preferensi petani terhadap nasi dari beberapa varietas di lokasi kegiatan disajikan pada Gambar 3. Secara keseluruhan tingkat kesukaan petani terhadap nasi varietas Rindang 2 lebih tinggi dibandingkan varietas lainnya, yaitu 96,7 persen dibandingkan Rindang 1 (76,7 persen), Inpago 10 (70,8 persen), Inpago 12 (80,0 persen) dan Ciherang (75,0 persen). Tingkat kesukaan yang tinggi terhadap nasi varietas Rindang 2 disebabkan kelebihan yang dimiliki baik terhadap rasa, aroma, warna dan tekstur nasi. Preferensi ini didukung oleh persepsi petani yang tinggi terhadap beras dan nasi pada varietas Rindang 2.

Dari empat indikator nasi, yaitu warna, rasa, aroma dan tekstur semua responden menganggap penting, hal ini terlihat dari kesukaan responden lebih dari 60 persen. Jika dilihat lebih jauh aroma nasi merupakan indikator yang paling disukai dengan tingkat kesukaan 86 persen, diikuti dengan warna nasi $(80,0$ persen), rasa nasi (77,3 persen) dan tekstur nasi (76,0 persen). Hasil yang sama diperoleh dari penelitian Yusuf dan Fitria (2017) bahwa masyarakat di Aceh lebih menyukai warna dan aroma sebagai indikator tingkat kesukaan terhadap nasi, berbeda dengan penelitian Aprilia, dkk. (2016); Ishaq dan Ruswandi (2018) rasa nasi yang enak untuk dikonsumsi merupakan indikator kesukaan tertinggi; Prayoga, dkk. (2018) mendapatkan hasil bahwa petani di Pangandaran dan Cilacap menjadikan tekstur dan aroma nasi menjadi indikator yang utama. Berdasarkan beberapa hasil penelitian tersebut mengindikasikan bahwa tingkat kesukaan (preferensi) masyarakat terhadap nasi antar daerah berbeda-beda yang disebabkan oleh kebiasaan masyarakat setempat. 


\section{KESIMPULAN}

Petani mempunyai persepsi yang baik terhadap karakter tanaman pada varietas Inpago 12 terutama pada indikator produktivitas tanaman. Persepsi yang baik terhadap karakter beras terutama pada indikator warna yang lebih putih/cerah diperoleh pada varietas Rindang 1 dan Inpago 12, sedangkan terhadap karakter nasi petani mempunyai persepsi yang baik pada tekstur nasi yang lebih pulen dan warna nasi yang cerah pada varietas Rindang 2, Inpago 10 dan Ciherang.

Preferensi petani terhadap karakter nasi VUB padi gogo tertinggi diperoleh pada varietas Rindang 2 (96,7 persen), diikuti varietas Inpago 12 (80,0 persen), Rindang 1 (76,7 persen), Ciherang (75,0 persen), dan Inpago 10 (70,8 persen). Berdasarkan hasil tersebut petani lebih menyukai karakter nasi VUB padi gogo varietas Rindang 2 karena memiliki rasa nasi yang lebih manis dan tekstur nasi yang pulen dibandingkan varietas lainnya. Sebagai saran untuk mengembangkan varietas padi gogo perlu memerhatikan produktivitas tanaman, warna dan ukuran beras serta rasa dan tekstur nasi.

\section{UCAPAN TERIMA KASIH}

Ucapan terima kasih disampaikan kepada Kepala Badan Penelitian dan Pengembangan Pertanian atas pembiayaan yang diberikan melalui DIPA BPTP Jawa Tengah TA 2020 pada kegiatan Pengkajian Teknologi Budidaya Larikan Padi Gogo (Largo) Super. Ucapan terima kasih juga disampaikan kepada Bapak Yuni Kamal Widayat sebagai teknisi BPTP Jawa Tengah, Bapak Parjiyanto dan Ibu Pipit Pramono sebagai petugas penyuluh lapangan (PPL) yang telah berkontribusi dalam pertemuan dengan kelompok tani, serta pengambilan data teknis maupun data sosial ekonomi kegiatan.

\section{DAFTAR PUSTAKA}

Aprilia, A., F. Laili, F, and Sujarwo. 2016. Consumer Preferences for Rice in Malang, East Java, Indonesia. Agricultural Socio-Economics Journal. Vol. 16(03): 136-142.

Ar-Rozi, M.F., S. Masithoh, dan H. Miftah. 2020. Analisis Persepsi Konsumen Beras Organik dan Faktor-Faktor yang Memengaruhinya (Kasus Orang Tua Siswa Sekolah Alam Indonesia Studio Alam, Depok). Jurnal Agribisains. Vol. 6(2): 89-99.
Badan Penelitian dan Pengembangan Pertanian. 2019. Deskripsi Varietas Unggul Baru Padi. Badan Penelitian dan Pengembangan Pertanian, Kementerian Pertanian, Jakarta.

Badan Pusat Statistik Provinsi Jawa Tengah. 2019. Jawa Tengah Dalam Angka 2019. Badan Pusat Statistik Provinsi Jawa Tengah, Semarang

Darsani, Y. R. and Koesrini. 2018. Preferensi Petani terhadap Karakter Beberapa Varietas Unggul Padi Lahan Rawa Pasang Surut. Jurnal Penelitian Pertanian Tanaman Pangan. Vol. 2(2): 85-94.

Hamdani, K. K, dan S. Murtiani. 2017. Kajian Inovasi Teknologi Varietas Unggul Baru (VUB) Padi Sawah Inbrida di Kabupaten Subang. Prosiding Seminar Nasional Padi. Balai Besar Padi Sukamandi. Badan Litbang Pertanian, pp. 139-146.

Hanas, D.F., E. Kriswiyanti, dan I Ketut Junitha. 2017 Karakter Morfologi Beras sebagai Pembeda Varietas Padi. Indonesian Journal of Legal and Forensic Sciences. Vol.1: 23-28

Haryati, Y., B. Nurbaeti, I. Noviana, dan A. Ruswandi. 2020. Pertumbuhan dan Hasil Beberapa Varietas Unggul Baru Padi di Kabupaten Majalengka. CR Journal. Vol. 06(02): 65-72.

Hasrawati, A., I. Kadekoh, dan A. Ete. 2017. Karakteristik Padi Gogo Lokal yang Diberi Bahan Organik pada Berbagai Ketersediaan Air. e-J. Agrotekbis. Vol. 5(2): 134-143.

Hermanasari, R., A. Hairmansis, A.P. Lestari, Yullianida, dan Suwarno. 2017. Evaluasi Preferensi Petani di Jawa Tengah terhadap Varietas Padi Gogo Melalui Seleksi Varietas Partisipatif. Prosiding Seminar Nasional PERIPI 2017: 255-264.

Husnain, D., Nursyamsi, dan M. Syakir. 2016. Teknologi Pemupukan Mendukung Jarwo Super. Jurnal Sumberdaya Lahan. Vol. 10(1): 1-10.

Indratanaya, I.G.N.S.D., I Dewa Putu Oka Suardi, dan Ida Ayu Listia Dewi. 2019. Persepsi Petani terhadap Program Upaya Khusus Peningkatan Produksi Padi, Jagung, dan Kedelai (Kasus Teknologi SRI di Subak Lungatad, Desa Peguyangan Kangin, Kecamatan Denpasar Utara, Kota Denpasar). E-Jurnal Agribisnis dan Agrowisata. Vol. 8(2): 225-232.

Ishaq, I., dan A. Ruswandi. 2018. Penggunaan Benih dan Preferensi Petani terhadap Karakteristik Varietas Unggul Padi pada Tiga Sentra Produksi Padi di Jawa Barat. CR Journal. Vol. 04(01): $1-12$.

Kikuta, M., Y. Yamamoto, and Y. B. Pasolon. 2016. How Growth and Yield of Upland Rice Vary with Topographic Conditions: A Case of Slash-andburn Rice Farming in South Konawe Regency, 
Southeast Sulawesi Province, Indonesia. Trop. Agr. Develop. Vol. 60(3): 162-171.

Krisnawati, Purnaningsih, N., dan Asngari, P. 2013. Persepsi Petani terhadap Peranan Penyuluh Pertanian di Desa Sidomulyo dan Muari, Distrik Oransbari, Kabupaten Manokwari Selatan. Sosio Konsepsia. Vol. 3(1): 301-312.

Mardiah, Z., A.T. Rakhmi, S.D. Indrasari, dan B. Kusbiantoro. 2016. Evaluasi Mutu Beras untuk Menentukan Pola Preferensi Konsumen di Pulau Jawa. Penelitian Pertanian Tanaman Pangan. Vol. 35(3): 163-180.

Nazirah, Laila dan dan B.S.J. Damanik. 2015. Pertumbuhan dan Hasil Tiga Varietas Padi Gogo Pada Perlakuan Pemupukan. Jurnal Floratek. Vol. 10: 54-60.

Nurhasanah, Sadaruddin, and W. Sunaryo. 2017. Yield-related traits characterization of local upland rice cultivars originated from East and North Kalimantan, Indonesia. Biodiversitas. Vol. 18(3): 2085-4722.

Pasolon, Y. B., C. Gago, D. Boer, F.S. Rembon, Muhidin, M. Kikuta, and Y. Yamamoto. 2017. Growth of Upland Rice in Variable Soil water-holding Capacity. Research Journal of Pharmaceutical, Biological, and Chemical Sciences. Vol. 8(2): 1608-1614.

Prayoga, M. K., N. Rostini, M. R. Setiawati, T. Simarmata, S. Stoeber, dan K. Adinata. 2018. Preferensi Petani terhadap Keragaan Padi (Oryza sativa) Unggul untuk Lahan Sawah di Wilayah Pangandaran dan Cilacap. Jurnal Kultivasi. Vol. 17(1): 523-530.

Rahayu, H. S., Risna and F. N. Fahmi. 2019a. Respon dan Kepuasan Petani terhadap Diseminasi Komponen Teknologi PTT Padi Sawah di Kabupaten Sigi Sulawesi Tengah. Prosiding Seminar Nasional Dalam Rangka Dies Natalis UNS Ke 43:7-14.

Rahayu, H. S., Muchtar, dan Saidah. 2019b. The Feasibility and Farmer Perception of True Shallot Seed Technology in Sigi District, Central Sulawesi, Indonesia. Asian Journal of Agriculture. Vol. 3(1): 16-21.

Ritonga, E. S., I. N. Istina, Usman, dan M. G. Wibisono. 2020. Kajian Adaptif VUB Padi Gogo Spesifik Lokasi di Provinsi Riau. Prosiding Seminar Nasional Lahan Suboptimal ke-8: 269-275.

Rohaeni, W. R., A. Sinaga, dan M. I. Ishaq. 2012. Preferensi Responden terhadap Keragaan Tanaman dan Kualitas Produk Beberapa Varietas Unggul Baru Padi (Studi Kasus dalam Mendukung Penyebaran VUB Padi Sawah di Kabupaten Karawang). Informatika Pertanian. Vol. 21(2): 97-103.
Sadimantara, G. R., W. Nuraida, N.W.S. Suliartini, and Muhidin. 2018. Evaluation of Some New Plant Type of Upland Rice (Oryza sativa L.) Lines Derived from Cross Breeding for The Growth and Yield Characteristics. IOP Conf. Series: Earth and Environmental Science, 157: 1-6.

Saleh, T. W., N. Buri, dan A. Saragih. 2020. Keragaan Hama, Penyakit dan Musuh Alami pada Budidaya Beberapa Varietas Padi Gogo di Lahan Sawah. Prosiding Temu Aplikasi Teknologi \& Seminar Nasional Pertanian dan Peternakan: 163-170.

Setyowati, I., dan S. Kurniawati. 2015. Preferensi Masyarakat terhadap Karakter Nasi Varietas Unggul Baru Padi: Kasus di Kecamatan Cibadak, Kabupaten Lebak, Banten. Prosiding Seminar Nasional Masy. Biodiv. Indon. Vol. 1(4): 889-893.

Shoidah, F., dan Adnan. 2021. Pertumbuhan dan Produktivitas 5 Varietas Unggul Baru Padi di LahanBukaan Baru Kabupaten Boven Digoel. Agrosains. Vol. 23(1): 6-11.

Sunanto, dan A. W. Rauf. 2018. Respons Petani terhadap Pelaksanaan Displai Padi Gogo VUB pada Lahan Sub Optimal di Sulawesi Selatan. Jurnal Sosial Ekonomi Pertanian. Vol. 14 (2): 143-160.

Sutaryo, B., dan S. Widodo. 2018. Kajian Keragaan Beberapa Varietas Unggul Baru Padi Gogo di Lahan Sub-Optimal Gunungkidul, Yogyakarta. Prosiding Seminar Nasional Lahan Suboptimal, pp. 449-455.

Theresia, V., A. Fariyanti, dan N. Tinaprilla. 2016. Analisis Persepsi Petani terhadap Penggunaan Benih Bawang Merah Lokal dan Impor di Kabupaten Cirebon, Jawa Barat. Jurnal Penyuluhan. Vol. 12(1): 74-88.

Wardani, C. 2019. Kinerja Ketahanan Beras di Indonesia: Komparasi Jawa dan Luar Jawa Periode 2005 - 2017. Jurnal Ketahanan Nasional. Vol. 25(1): 107-130.

Widyastuti, E. Widiyanti dan Sutarto. 2016. Persepsi Petani terhadap Pengembangan System of Rice Intensification (SRI) di kecamatan Moga, Kabupaten Pemalang. Agrista. Vol. 4(3): 476485.

Yusuf, H., dan E. Fitria. 2017. Persepsi dan Preferensi Petani terhadap Varietas Unggul Baru (VUB) Padi di Provinsi Aceh. Jurnal Triton. Vol. 8(1): 57-66. 


\section{BIODATA PENULIS :}

Dewi Sahara dilahirkan di Pati, 6 Desember 1968. Penulis menyelesaikan pendidikan S1 Budidaya Tanaman Universitas Hasanuddin Makassar tahun 1992, S2 Ekonomi Pertanian Universitas Gadjah Mada Yogyakarta tahun 2001 dan S3 Ekonomi Pertanian di IPB Bogor lulus tahun 2011.

Chanifah dilahirkan di Magelang, 29 Desember 1981. Penulis menyelesaikan pendidikan S1 pada Program Studi Agribisnis di Institut Pertanian Bogor pada tahun 2010, dan S2 Program Studi Ekonomi Pertanian di Universitas Gadjah Mada pada tahun 2019

Elly Kurniyati dilahirkan di Bogor, 13 September 1973. Penulis menyelesaikan S1 Sosial Ekonomi Pertanian Universitas Sebelas Maret tahun 1997.

Budi Hartoyo dilahirkan di Brebes, 15 Juli 1963. Penulis menyelesaikan pendidikan S1 Agronomi Fakultas Pertanian Universitas Tunas Pembangunan Surakarta tahun 1987, S2 Budidaya Tanaman Universitas Gadjah Mada Yogyakarta tahun 2002, S3 Budidaya Tanaman Departemen Agronomi dan Hortikultura, Fakultas Pertanian Institut Pertanian Bogor tahun 2012. 
Halaman ini sengaja dikosongkan 